\title{
Candida tropicalis endophthalmitis following penetrating keratoplasty
}

\author{
Wolfgang Behrens-Baumann, Reinhard Ruechel, Ortrud Zimmermann, Martin Vogel
}

\begin{abstract}
A case of Candida tropicalis endophthalmitis following penetrating keratoplasty is presented. The donor was an alcoholic, who died of bronchopneumonia and pancreatitis. We presume the candida infection was transmitted by the donor because Candida tropicalis was cultured in life from the donor's throat swab and corresponding fungal elements were discovered post mortem in kidney sections of the donor.
\end{abstract}

Transmission of infectious agents, including fungi, by donor tissue is a well known complication of corneal transplantation. ${ }^{12}$ However, there have been only two reports of Candida albicans endophthalmitis after keratoplasty. ${ }^{34}$ This is the first report of an intraocular infection by Candida tropicalis following corneal transplantation from a donor with Candida tropicalis sepsis.

\section{Case report}

A 76-year-old woman with aphakic bullous keratopathy and high myopia in both eyes, but otherwise healthy, underwent a penetrating keratoplasty on her right eye. The patient received antibiotic ointment before and after surgery and dexamethasone phosphate for the following three weeks. On day 2 and day 10 a vitreous cloudiness was noted, which disappeared subsequently, and the patient was discharged from hospital.

She returned to hospital on day 24 with infiltrates in the inner layers of the donor tissue, white fibrin clots in the anterior chamber, and a leucocoria. Smears from the conjunctiva were positive for Staphylococcus epidermidis. Topical tobramycin and systemic cefotaxime were administered without any effect.

On days 35 and 40 after the keratoplasty white intraocular material was removed by vitrectomy. Both aspirates were positive for Candida tropicalis. Antimycotic therapy was initiated with daily natamycin ointment and $0.75 \mu \mathrm{g}$ amphotericin-B injections into the anterior chamber every third day. On day 50 no fungi could be cultured from an aspirate of aqueous humour. Her visual acuity increased to $20 / 40$, and the corneal transplant was centrally clear.

One year later the patient underwent penetrating keratoplasty on her left eye without any complication. The donor of the first keratoplasty was a 54-year-old female alcoholic, who died of bronchopneumonia and pancreatitis. Candida tropicalis was cultured in life from a throat swab, and similar fungal elements were discovered postmortem in sections of the kidney by Fungiqual staining. On explantation, the second corneal button of the donor showed white infiltrates and was discarded.

\section{Discussion}

We suppose that in our patient Candida tropicalis was transmitted by infected donor tissue, particularly since $C$. tropicalis does not belong to the normal human microbial flora. The predisposition of alcoholics to candidosis is well known. ${ }^{5}$ Although the donor did not fulfil the exclusion criteria for donor corneas, ${ }^{6}$ the infiltration of the discarded corneal button and the history of alcoholism of the donor should have been a reason for discarding the first cornea which resulted in endophthalmitis. To avoid candidal transmission we suggest that at least immunocompromised donors (including alcoholics) are tested serologically for candidal antigen. Such tests can be performed within 30 minutes in the clinical laboratory. Test kits are available. The tests allow the identification of patients suffering from deep-seated and disseminated candidosis.

1 Ghandi SS, Lamberts DW, Perry HD. Donor to host transmission of disease via corneal transplantation. Surv Ophthalmo 981; 25: 306-11

2 Levenson JE, Duffin RM, Gardner SK, Pettit TH Dermatiaceous fungal keratitis following penetrating keratoplasty. Ophthalmic Surg 1984; 15: 578-82.

3 Insler MS, Urso LF. Candida albicans endophthalmitis after penetrating keratoplasty. Am f Ophthalmol 1987; 104: 57-60.

4 Weiss JL, Parker WT. Candida albicans endophthalmitis following penetrating keratoplasty. Arch Ophthalmol 1987; 105: 173 .

5 Odds FC. Candida and candidosis. London: Baillière, Tindall, 1988: 210.

Ophthaimology, University

Strasse 40, D-3400

Goettingen, Germany.

Accepted for publication 19 February 1991 eds. The cornea. New York: Churchill Livingstone, 1988: 713-24.
6 Bourne WM Corneal preservation. In: Kaufmann $\mathrm{HE}$, et al, 